\title{
Explotação de rochas ornamentais e meio ambiente
}

\section{Exploitation of Ornamental Stones and the Environment}

\author{
Erika Silva FABRI* \\ Hermínio Arias NALINI JÚNIOR** \\ Mariangela Garcia Praça LEITE ${ }^{* * *}$
}

\begin{abstract}
RESUMO
Apesar de as atividades minerárias serem fundamentais para a economia de diversos países, inclusive o Brasil, seu desenvolvimento não se dá sem que haja algum tipo de degradação ambiental. Os recursos minerais não são recursos renováveis e, portanto, uma vez extraídos, não podem ser substituídos, ou seja, é necessário que sejam utilizados de forma correta e responsável, levando em consideração o desenvolvimento sustentável. Portanto, dentre outros aspectos, é necessário que as minerações antevejam o tratamento e a disposição dos resíduos gerados ou até mesmo a sua devolução ao meio ambiente. Assim, o objetivo principal deste trabalho é apresentar os diferentes tipos de lavras de rochas ornamentais, seus métodos e suas implicações sobre o meio ambiente. Ao longo do trabalho, são apresentados os principais impactos ambientais causados pelas minerações de rochas ornamentais, bem como a importância da recuperação das áreas degradadas por elas. Um melhor planejamento das extrações de rochas ornamentais definiria com maior precisão a viabilidade econômica do empreendimento e diminuiria os impactos ambientais negativos. Além disso, o fim das irregularidades seria possível com a intensificação das ações de políticas públicas, do monitoramento e da fiscalização.
\end{abstract}

Palavras-chave: rocha ornamental; impactos ambientais; comunidade local; recuperação das áreas degradadas.

\begin{abstract}
Despite of the mining activities being fundamental for the economy of many countries, including Brazil, its development does not occur without some kind of environmental degradation. Mineral resources are not renewable, so, once extracted, they cannot be replaced. In other words, they must be used in a correct and responsible way, aimed at a sustainable development. In this way, among other things, it is necessary that mining companies foresee the treatment and disposal of waste generated or even its return to the environment. Thus the main objective of this paper is to present the different types of ornamen-
\end{abstract}

\footnotetext{
"Mestra em Evolução Crustal e Recursos Naturais (UFOP). Doutoranda do Programa de Pós-Graduação em Evolução Crustal e Recursos Naturais pela Universidade Federal de Ouro Preto (UFOP). Email: erikafabri@degeo.ufop.br

"* Doutor em Géologie Minière (Ecole Des Mines de Paris e Ecole Des Mines de Saint Etienne). Professor do Departamento de Geologia (Degeo) da Universidade Federal de Ouro Preto (UFOP). Email: nalini@degeo.ufop.br

*** Doutora em Engenharia Civil (UFRJ). Professora da Universidade Federal de Ouro Preto (UFOP). Email: garcia@degeo.ufop.br
} 
tal stone mines, its methods and its implications on the environment. Throughout this work, the main environmental impacts caused by mining of ornamental stones are presented, as well as the importance of rehabilitation of the degraded areas. A better extraction planning of ornamental stones would define more precisely the economic viability of the enterprise and would reduce the negative environmental impacts. In addition, the end of the irregularities would be possible with the intensification of public policy, monitoring and enforcement.

Keywords: ornamental stone; environmental impacts; local community; recovery of degraded areas.

\section{Introdução}

A mineração é uma atividade essencialmente destrutiva, com a qual o meio ambiente sofre degradação em favor do progresso da economia. As operações de mineração comumente envolvem o desmatamento e a destruição de habitats e da biodiversidade local. Além disso, extração e beneficiamento mineral podem levar à poluição ambiental. No entanto, o ser humano não pode desistir dos recursos minerais, usados como matérias-primas básicas para o seu desenvolvimento. Como bem coloca Chauhan (2010), um meio ambiente preservado oferece segurança ecológica para a humanidade, porém pode levar ao não crescimento econômico e tecnológico. Ou seja, as explorações minerais são indispensáveis na contribuição para a melhoria de vida e para o conforto do ser humano, além de serem de grande importância para a economia do país. Todavia, é fundamental que as minerações realizem suas atividades com responsabilidade social e ambiental, sempre considerando os princípios do desenvolvimento sustentável (FARIAS; COELHO, 2002).

Os recursos minerais não são recursos renováveis e, portanto, uma vez extraídos, não podem ser substituídos, ou seja, é necessário que sejam utilizados de forma correta e responsável, sem desperdício, prevendo não apenas o ganho imediato, mas também o bem das gerações futuras, levando em consideração os princípios do desenvolvimento sustentável. As explotações minerais acompanhadas de restauração ambiental, regeneração das áreas mineradas e utilização criteriosa dos recursos minerais extraídos são as alternativas mais viáveis para o crescimento econômico aliado à preservação do meio ambiente.

No Brasil, surgiram, na década de 1980, rigorosas leis que contribuíram e ainda contribuem para o orde- namento ambiental nacional. Entre elas, destacam-se: Política Nacional de Meio Ambiente, Ação Civil Pública, Plano Nacional de Gerenciamento Costeiro, Crimes Ambientais, Política Nacional de Educação Ambiental e Sistema Nacional de Unidades de Conservação da Natureza (SIQUEIRA, 2002). A Política Nacional de Meio Ambiente, Lei 6.938, de 31/8/1981, considerada um marco na política ambiental, institui o Sistema Nacional de Meio Ambiente. Inseriu para o direito ambiental brasileiro o conceito de Meio Ambiente, com o objetivo de proteger o meio ambiente em seus vários aspectos (SIQUEIRA, 2002). Nesta lei, estão os fundamentos que definem a proteção ambiental e que, posteriormente, foram regulamentados por meio de decretos, normas, resoluções e portarias. A resolução CONAMA 001/86, que regulamentou a Lei 6.938, de 31/8/1981, definiu os empreendimentos passíveis de Licenciamento Ambiental, e entre eles está a mineração. Tornou-se obrigatório, a partir desta resolução, o licenciamento ambiental para qualquer tipo de extração mineral. O mais importante instrumento para a concessão deste licenciamento é o EIA/RIMA, Estudo de Impactos Ambientais/Relatório de Impactos Ambientais. Mais especificamente, no caso do Estado de Minas Gerais, em novembro de 2008 foi instituída a Deliberação Normativa 124, que estabelece as diretrizes e os procedimentos para avaliação ambiental da fase de fechamento de mina. Esta deliberação determina que o fechamento da mina deve ser planejado desde a concepção do empreendimento, de forma a garantir que, após o fechamento da mina, os impactos ambientais, sociais e econômicos sejam mitigados, garantindo que, mesmo após o fechamento, a área da mina se mantenha em condições seguras e estáveis, com a aplicação de técnicas de controle e monitoramento. Além disso, determina que a área impactada pela atividade minerária tenha 
um uso futuro que respeite os aspectos socioambientais e econômicos da área de influência do empreendimento.

As respostas à questão ambiental nas empresas, segundo Donaire (1994), ocorreram em três fases. A primeira fase ficou concentrada no controle ambiental nas saídas, ou seja, muitas empresas começaram o seu controle ambiental com a instalação de equipamentos de controle da poluição nas saídas, como, por exemplo, chaminés e rede de esgoto. A segunda fase, conduzida pela insatisfação da população, passou a ser uma função da produção, levando às empresas a integração do controle ambiental nas práticas e processos industriais. Neste momento, o princípio básico do controle ambiental nas empresas foi a prevenção, envolvendo a seleção de matérias-primas ambientalmente corretas, o desenvolvimento de novos processos e produtos que não poluam o meio ambiente, o reaproveitamento da energia, a reciclagem de resíduos, entre outros. Depois disto, como a preocupação com o meio ambiente não parou de crescer, o consumidor passou a se preocupar com o conteúdo dos produtos e a maneira como eles eram produzidos pelas empresas, recusando os mais agressivos ao meio ambiente e levando à terceira fase: a integração do controle ambiental na gestão administrativa.

Apesar de ser considerada uma das legislações ambientais mais avançadas do mundo, o arcabouço legal brasileiro não conseguiu controlar totalmente os problemas ambientais gerados pelas minerações sobre os ecossistemas. Muitas empresas - especialmente as de pequeno porte - e garimpos clandestinos continuam a degradar grandes áreas, abandonando-as sem qualquer tipo de recuperação. Neste contexto, o presente trabalho tem por objetivo apresentar as diversas maneiras de extração de rochas ornamentais, seus métodos de lavra e suas implicações sobre o meio ambiente. Para tal, são listados os diferentes tipos de lavras existentes para extração de rochas ornamentais, seus principais impactos causados desde a abertura da mina até o seu fechamento e/ou abandono da área, além dos problemas advindos da utilização do método de lavra por matacões e por maciços rochosos. Por fim, é destacada a importância da recuperação das áreas degradadas pelas minerações e sua influência na comunidade local.

\section{Lavra de rochas ornamentais}

A explotação de rochas ornamentais é uma atividade extrativista onde as principais características são o processamento dos recursos naturais, o investimento de pouca tecnologia e a não exigência de uma escala mínima de produção (SPÍNOLA et al., 2004). As minas são, em sua maioria, a céu aberto e podem ocorrer em maciços rochosos e/ou em matacões. Segundo Matta (2003), as lavras de maciços rochosos são mais comuns por possuírem maiores reservas e maior produção. Neste caso, a verificação da existência de impurezas, trincas, alterações, topografia local, entre outras características é de extrema importância para o bom aproveitamento da reserva mineral e uma menor geração de rejeitos (REIS; SOUSA, 2003). Já os matacões são porções individualizadas de maciços rochosos, são corpos de rocha arredondados que se soltam de maciços rochosos por efeito de desgaste erosivo físico, químico e/ou biológico. As lavras em matacões são mais simples, com custos mais baixos, normalmente associados à abertura de estradas de acesso. Além disso, possuem baixo custo operacional e reduzido investimento inicial, necessitando de pouca tecnologia e de mão de obra pouco ou não qualificada. $\mathrm{O}$ processo de esquadrejamento dos blocos é feito por meio do uso de pólvora negra, marteletes e cunhas individuais, obedecendo a um procedimento padrão (REIS; SOUSA, 2003). Porém, são atividades com grandes problemas ambientais, já que produzem grandes quantidades de rejeitos devido às impurezas e alterabilidade dos minerais e às heterogeneidades da rocha (COELHO; VIDAL, 2003; ROCHA; SOUSA, 2010).

Diferentemente do que ocorre com as lavras de matacão, onde as opções para explotação são limitadas, as minas em maciços rochosos possibilitam a aplicação de diferentes técnicas de exploração (MATTA, 2003). Dentre os principais métodos de lavra para estas minas, destacam-se: tipo fossa, tipo poço, por bancadas baixas, por bancadas altas, por desabamento e subterrânea.

Segundo Reis e Sousa (2003), a atividade de lavra por bancadas altas se dá quando o maciço rochoso possui altura mínima de 6 metros e máxima de 16 metros. Este método é adotado quando a rocha apresenta heterogeneidade qualitativa e estrutural (MATTA, 2003) e quando 
a seleção da lavra é de difícil realização (ROCHA; SOUSA, 2010). De acordo com Reis e Sousa (2003), a abertura das bancadas varia de 3 a 6 metros de largura e 40 metros de comprimento. Diferentes tecnologias podem ser utilizadas, sendo a principal delas o corte dos blocos com o uso do fio diamantado. O método de lavra por bancadas altas, comparado com o método de bancadas baixas, necessita de uma maior quantidade de mão de obra qualificada, além de grande quantidade de equipamentos e mais sofisticados, se tornando assim um método mais oneroso. Além disso, são de difícil recuperação ambiental (COELHO; VIDAL, 2003). A frente de lavra por bancadas baixas se dá quando a jazida é composta por material mais homogêneo. Este método possui bancadas horizontais baixas, sendo a altura da bancada correspondente à dimensão de um bloco comercializável (MATTA, 2003). Em geral, as dimensões finais não devem ultrapassar 3,0 metros, de forma a permitir que o bloco final seja retirado da cava com dimensões adequadas à comercialização. Esse método favorece a maior estabilidade das frentes de lavra (COSTA, 2009), possibilitando um controle minucioso e maior segurança no trabalho, pois evita ou reduz de forma considerável o risco de acidentes graves. Possui menor impacto visual, além de favorecer uma melhor recuperação ambiental. Extrações minerais por bancadas baixas geralmente acontecem em terrenos com relevo mais suave e suas frentes de lavra são mais extensas, facilitando, assim, a movimentação de equipamentos e de blocos (REIS; SOUSA, 2003). Tanto a lavra do tipo fossa como a lavra do tipo poço são variações da lavra por bancadas, sendo a do tipo poço uma evolução da lavra do tipo fossa. São métodos usados em jazidas encontradas em depressões no terreno (MATTA, 2003). Apresentam pequeno impacto visual, porém atingem facilmente o lençol freático, sendo o bombeamento de água do interior da cava quase sempre necessário em todo o processo de produção (REIS; SOUSA, 2003). A maior diferença entre os dois métodos é o tamanho das rampas laterais das frentes de lavra, com rampas das lavras do tipo poço maiores, mais íngremes e muitas vezes verticais, com grandes riscos de acidentes de trabalho. A lavra por desabamento é um método que consiste no desmonte da rocha por explosivos (ROCHA; SOUSA, 2010), aplicada em maciços rochosos bem fraturados e com relevo acidentado - acima de $45^{\circ}$ (MATTA, 2003). É um método que depende de pouco conhecimento técnico e de baixo custo inicial e operacional. Como gera uma grande quantidade de material fragmentado, com formas muito irregulares, esta tecnologia vem sendo abandonada e utilizada apenas em áreas onde são poucas as reservas e grandes as áreas disponíveis para deposição do material estéril (ROCHA; SOUSA, 2010). A lavra subterrânea é pouco utilizada devido ao grande número de depósitos de rochas ornamentais aflorantes ou próximos à superfície (REIS; SOUSA, 2003). Segundo Rocha e Sousa (2010), este método consiste na passagem progressiva da lavra a céu aberto para a lavra subterrânea quando se deseja aproveitar ao máximo a disponibilidade da jazida. Foi o que aconteceu na principal mina subterrânea de rocha ornamental localizada nos EUA, no Estado de Vermont (DUARTE, 1998, citado por REIS; SOUSA, 2003). Sua operação foi iniciada em 1870 a céu aberto, passando a subterrânea em 1907. No que diz respeito ao impacto ambiental causado, este método leva vantagem, sendo o de menor impacto na superfície (ROCHA; SOUSA, 2010). Por outro lado, há grandes problemas relativos ao controle de estabilidade, dificuldades operacionais, maior probabilidade de ocorrer acidentes e ainda custo de lavra mais alto que a lavra a céu aberto (REIS; SOUSA, 2003).

\section{Impactos ambientais gerados pelas minerações de rochas ornamentais}

Os impactos ambientais das minerações de rochas ornamentais começam ainda com as fases de prospecção e pesquisa mineral e prosseguem com a abertura da frente de lavra, implantação do empreendimento, extração, beneficiamento e refino da rocha propriamente dita (ALMEIDA, 2006b). Os principais efeitos ambientais são o ultralançamento de fragmentos, a geração de vibrações no terreno, a emissão de materiais particulados (poeira) na atmosfera, o aumento dos níveis de ruído, o assoreamento de redes de drenagens adjacentes às minerações, além da alteração visual e paisagística (FERREIRA et al., 2006).

$\mathrm{Na}$ fase de prospecção e pesquisa mineral, apesar de pequeno, o impacto ao meio ambiente já existe. No 
entanto, é na fase inicial que a degradação ambiental começa a se agravar, com o desmatamento e a remoção do solo para a abertura da frente de lavra e vias de acessos, tornando viável a operação de extração da rocha (COSTA, 2009). Neste momento, já é possível identificar efeitos negativos sobre a fauna e a flora e, principalmente, o impacto visual causado (SOUSA, 2007). Dependendo do local, o desmatamento é o principal e mais característico impacto causado pela atividade minerária (LIMA; FALCÃO, 2009), que ainda tem como consequências focos de erosão, escorregamento de massas de solo e/ ou de rochas, assoreamento de cursos d'água e a perda da qualidade do ar devido à emissão de partículas finas proveniente da movimentação do solo (COSTA, 2009). O solo e o material estéril são, normalmente, acumulados nas vizinhanças da mina, muitas vezes sem o uso de técnicas adequadas de contenção. Quanto maior a quantidade do material acumulado, mais instáveis e sujeitos a escorregamentos localizados. Nos períodos chuvosos, estes materiais podem ser removidos e transportados até as regiões mais baixas, se direcionando, muitas vezes, para cursos d'água, o que pode ocasionar o assoreamento gradativo dos mesmos. A poluição visual, consequência tanto do desmatamento quanto da remoção do solo, é o primeiro efeito visível da mineração. Enormes buracos, lagos, paredões e áreas degradadas são deixados pela mineração na maioria dos casos, impedindo a posterior utilização do terreno (LIMA; FALCÃO, 2009). Passadas a fase inicial e a fase de instalação do projeto, as operações da mina se iniciam e, em sua maioria, com o uso de detonação de explosivos. Nas lavras por desabamento, o uso de explosivo tem como consequências principais a geração de ruídos, vibrações e geração de poeira, quase sempre prejudiciais à tranquilidade da população que circunvizinha o empreendimento. E, ainda, o deslocamento de ar causado por essas detonações e a intensidade da onda de choque, que se propaga por toda a massa rochosa, coloca em risco as construções situadas próximas à lavra.

Outro problema ambiental causado pela mineração de rochas ornamentais é a geração e disposição de rejeitos. De acordo com Williams et al. (1997), rejeito é toda substância não econômica, separada do material de interesse pelo beneficiamento da rocha e estéril à substância natural (rocha, solo e subsolo) não aprovei- tável economicamente que ocorre em camadas sobre o material de interesse. No caso de extração de rocha ornamental, entende-se como rejeito todo fragmento de rocha retirado do bloco para deixá-lo nas dimensões exigidas pelos mercados externo e interno, ou seja, fragmento de rocha não aproveitável economicamente, em função de suas dimensões reduzidas ou irregulares (ALMEIDA, 2006a). O grau de degradação ambiental é, consequentemente, diretamente proporcional ao volume e ao tipo de rejeitos produzidos. Semelhante ao que acontece com os estéreis, o carreamento pelas águas pluviais de sedimento fino das áreas de depósitos de rejeitos pode ocasionar, nos cursos d'água atingidos, o aumento da turbidez e das partículas em suspensão (MARQUES, 2001, citado por ALMEIDA, 2006a), culminando com o seu assoreamento.

Normalmente, a contaminação química das minas de rochas ornamentais é pequena e se restringe a possíveis resíduos de óleo diesel usados nas máquinas e pólvora negra proveniente dos explosivos usados no desmonte de rochas e aos resíduos finos produzidos durante a fase de beneficiamento da rocha (serragem, corte, polimento e acabamento). Neste caso, a geração de grande volume destes resíduos, dependendo do tipo de rocha, pode liberar elementos-traço para a água quando acumulado nos cursos d'água (ALMEIDA 2006a). Um dos maiores transtornos sofridos pelos trabalhadores das minerações e habitantes próximos a essa mineração relaciona-se à emissão deste material particulado (provocando ou aumentando os problemas respiratórios), que fica em suspensão no ar, sendo transportado pelo vento por extensas áreas (LIMA; FALCÃO, 2009).

\section{Principais problemas ambientais das lavras de matacões}

Os principais impactos causados pelo método de lavra por matacões são os visuais, causados pelo desmatamento, e o carreamento do solo removido pelas chuvas para os cursos d'água próximos à lavra. Os matacões, na sua grande maioria, são encontrados soterrados por regolitos, gerando a necessidade de remoção do solo para a extração da rocha. Quando este processo acontece sem nenhum controle, gera grandes impactos ambientais no 
local e, principalmente, nas redes de drenagem próximas. Destaca-se também a grande quantidade de rejeitos produzidos, resultado de quatro fatores (MATTA, 2003):

$\checkmark$ Uso de explosivos: a deflagração de explosivos proporciona a criação de microfraturas, podendo comprometer a integridade da rocha, o que ocasiona perda de material. Levando em consideração que os matacões ocorrem pontualmente, se o uso de explosivo ocasionar a perda do material ali presente, a lavra tornar-se-á inviável;

$\checkmark$ Ação das intempéries: os matacões são corpos de rocha que se soltaram de maciços rochosos, muitas vezes rolados pela superfície da terra, portanto, é provável que tenham sofrido bastante com o intemperismo, gerando maior produção de solo e estéreis;

$\checkmark$ Heterogeneidade do corpo rochoso: a chance de o corpo rochoso não ser homogêneo é muito grande nesse tipo de lavra. E, neste caso, essa heterogeneidade pode comprometer os padrões estéticos dos blocos extraídos, prejudicando o planejamento da produção, restringindo o comércio e gerando mais rejeitos;

$\checkmark$ Forma geométrica e dimensões dos corpos rochosos individualizados: a geração de rejeitos é ainda maior por causa da exigência da forma geométrica do bloco comercializável (paralelepípedo com ângulos retos). Na lavra por matacões, as partes arredondadas dos matacões sobraram como rejeito. Além disso, as dimensões dos corpos rochosos individualizados também favorecem a produção de rejeitos, uma vez que as dimensões dos matacões, na maioria das vezes, não correspondem às dimensões exigidas pelo mercado.

Além destes, a poluição causada por equipamentos, utensílios domésticos, ferramentas e outros objetos, a poluição com o derramamento de óleo e combustíveis das máquinas e a poluição sonora gerada por marteletes pneumáticos (Jet Flame) são outros impactos negativos ao meio ambiente esperados desse tipo de lavra (MATTA, 2003).

\section{Principais problemas ambientais das lavras de maciços rochosos}

Como na lavra de maciços rochosos utilizam-se tecnologias mais avançadas e as jazidas são mais bem aproveitadas devido às suas dimensões, estas tendem a poluir menos e atender melhor ao mercado consumidor. Entretanto, a degradação ambiental também ocorre, sendo seus principais impactos ambientais (MATTA, 2003):

$\checkmark$ Desmatamento das áreas a serem exploradas e para disposição de rejeitos e estéreis;

$\checkmark$ Decapeamento e remoção do solo para a explotação do maciço rochoso;

$\checkmark$ Disposição inadequada dos rejeitos e estéreis;

$\checkmark$ Lixo doméstico gerado pelos trabalhadores das minerações, que, na maioria das vezes, são jogados nas áreas que circunvizinham a frente de lavra;

$\checkmark$ Sucatas metálicas dispostas e posteriormente abandonadas na área da mineração;

$\checkmark$ Efluentes líquidos, tais como esgoto doméstico, óleos lubrificantes e produtos de limpeza, que não passam por um processo de tratamento antes de serem lançados no meio ambiente;

$\checkmark$ Poluição atmosférica, como poeiras e fumaças, gerada pelas frentes de lavra, que atinge as comunidades próximas à mineração;

$\checkmark$ Poluição sonora e vibrações provocadas pelos equipamentos de desmonte da rocha, como maçaricos, perfuratrizes, detonações, além da circulação constante de veículos pesados.

A geração rejeitos é sem dúvida o maior problema ambiental desse tipo de lavra, sendo sua produção dependente principalmente dos métodos de lavra escolhidos para explotação da rocha. Porém, outros fatores podem influenciar para o aumento do rejeito gerado, como, por exemplo, o mercado, que geralmente segue tendências de moda arquitetônica, ou seja, a comercialização de um tipo de rocha ornamental pode hoje estar em alta e amanhã o material não ser mais aceito no mercado (tanto externo quanto interno), passando de bloco comercializável a rejeito. Os tipos de estrutura das rochas, as condições físicas da rocha, o nível de homogeneidade e geometria do depósito também podem influenciar na quantidade final de rejeito gerado (MATTA, 2003). 
Recuperação de áreas degradadas pela mineração de rochas ornamentais

Nas áreas lavradas, as medidas usualmente empregadas para a recuperação ambiental são: inicialmente, o remodelamento topográfico da área, que consiste em recompor a topografia do terreno, gerada após as atividades minerárias; a instalação de sistemas de drenagem; a reaplicação da camada orgânica do solo previamente estocada (topsoil), caso exista, ou então a correção de pH e nutrientes do solo; finalmente, faz-se a revegetação da área (BITAR, 1997). Nas áreas de disposição de estéreis e rejeitos, as medidas de recuperação normalmente empregadas são semelhantes, com o retaludamento das pilhas, correção do solo e posterior revegetação. Além disso, já durante a fase de explotação devem ser instaladas caixas de sedimentação e/ou bacias de decantação de rejeitos a jusante do sistema de drenagem da área e feitos o redimensionamento ou construção de extravasores ou vertedouros em barragens de rejeito, o tratamento de efluentes (líquidos ou sólidos em suspensão) das bacias de decantação de rejeitos, o tratamento de águas lixiviadas em pilhas de rejeitos e estéreis e o tratamento de águas subterrâneas possivelmente contaminadas (BRUM, 2000). Nas áreas de infraestrutura e nas áreas que circunvizinham o empreendimento mineiro, as medidas que melhor se ajustam são a captação e desvio de águas pluviais, a captação e reutilização das águas utilizadas no processo produtivo, com sistemas adicionais de proteção dos cursos d'água, a coleta e tratamento de resíduos (esgotos, óleos, graxas), a dragagem de sedimentos em depósitos de assoreamento, a implantação de barreiras vegetais e a execução de reparos em áreas circunvizinhas afetadas pelas atividades da mineração (OLIVEIRA JR., 1998).

É importante ressaltar que a camada de solo superficial orgânico, retirada quando da abertura da frente de lavra, pode ser estocada de maneira adequada e ser reutilizada na recuperação das superfícies lavradas e/ou nos depósitos de estéreis e/ou rejeitos. Sua reutilização pode ser também na construção de diques, aterros, murundus ou leiras de isolamento e barragens, na recomposição das superfícies topográficas e paisagens, contenção ou retenção de blocos rochosos instáveis, entre outras. Assim como o solo superficial orgânico, os estéreis também podem ser aproveitados no preenchimento da área lavrada tentando recompor a topografia e a paisagem local. Segundo Ribeiro e Ferreira (2007), os rejeitos gerados no beneficiamento das rochas ornamentais já estão ganhando outros destinos. Lentamente, algumas técnicas vão sendo estabelecidas para o emprego desses materiais. Os rejeitos finos provenientes do corte de mármore já estão sendo utilizados como corretivos de acidez do solo, como matéria-prima para a indústria de cimento, como dessulfurante em centrais termoelétricas que utilizam carvão com alto teor de enxofre, como carga na fabricação de papel, PVC e tintas e como matéria-prima para argamassa industrializada (MINEROPAR, 2006 e STELLIN JR.; CARUSO, 2004, citados por RIBEIRO; FERREIRA, 2007). Resíduos finos gerados no beneficiamento de gnaisses podem substituir a cal na formulação de argamassas industriais (CARVALHO et al., 2004, citados por RIBEIRO; FERREIRA, 2007) e podem ser utilizados também como fundentes na formulação da massa cerâmica para produção de telhas (VIANA, 2003, citado por RIBEIRO; FERREIRA, 2007). Por fim, os rejeitos mais grosseiros normalmente são estocados nas áreas adjacentes às frentes de lavra, porém, podem ser utilizados na produção de artesanato de pedras ou na produção de blocos pequenos para calçamento, os "paralelos" ou "paralelepípedos". Algumas empresas apresentam como alternativa a produção de britas para a construção civil ou a produção de seixos ornamentais (no caso de mármores), mas isso somente é possível se a mineração extrair apenas um tipo de rocha ornamental (RIBEIRO; FERREIRA, 2007).

\section{Relação mineração e comunidade local}

Junto com o surgimento das primeiras minerações, começaram também as dificuldades de convivência da empresa e da população circunvizinha à área minerada. Apesar da geração de empregos e do crescimento econômico associado, a sociedade vem se questionando sobre a responsabilidade socioambiental da atividade mineral, levantando dúvidas sobre o retorno que a mineração traz para as comunidades que abrigam seus empreendimentos (FERNANDES et al., 2009). Afinal, é a população 
do entorno que terá que conviver com poluição, ruído, vibrações, dentre outros (RIBEIRO; FERREIRA, 2007). Ou seja, além dos diversos impactos negativos causados pelas extrações de rochas ornamentais ao meio ambiente, desde o seu desenvolvimento até o abandono da área após o encerramento das atividades de lavra, a mineração ainda é uma atividade que expõe a altos riscos a vida e a saúde do ser humano. Por isso, são cada vez maiores a pressão da população e a exigência de tomadas de medidas capazes de compensar ou anular os impactos negativos causados pelas minerações, por exemplo, com a aplicação de programas de preservação e recuperação/ restauração ambiental (CARVALHO, 2004).

A falta de cuidados específicos em relação à segurança e ao conforto ambiental das populações que circunvizinham as áreas de exploração mineral, aliada ao descumprimento da legislação, tanto por parte das empresas mineradoras quanto pelo poder público (muitas vezes por despreparo deste), agrava ainda mais a relação empresa/comunidade/órgãos governamentais. Para complicar ainda mais, os municípios, quase sempre, ficam de mãos atadas pela falta de planos diretores municipais que lhes daria o direito de intervir nas questões ambientais, além da falta de interesse dos órgãos encarregados da fiscalização das atividades minerárias e/ou de expansão urbana (FERREIRA et al., 2006).

\section{Considerações finais}

O uso dos recursos naturais não renováveis reduz sua quantidade e pode comprometer o desenvolvimento das gerações futuras. No entanto, isso não significa que

\section{Referências}

ALMEIDA, A. D'A. de. Uso da camada superficial de solo na revegetação do estéril da extração de granito. Tese (Doutorado) - Universidade Federal de Viçosa. 57 p. Viçosa, 2006a.

ALMEIDA, S. Lavra, artesanato e mercado do esteatito de Santa Rita de Ouro Preto, Minas Gerais. Dissertação (Mes- eles não devam ser extraídos. O seu uso pelas gerações atuais deve ser feito de maneira responsável, levando em consideração a sua disponibilidade no meio ambiente. Além disso, é importante fazer o uso de tecnologias que minimizem seu esgotamento, dosem sua exaustão e deem ênfase à sua reciclagem e ao seu uso econômico para garantir que o recurso não se esgote. As minerações de rochas ornamentais têm um importante papel na economia de um país, porém, provocam grandes degradações ao meio ambiente. Os impactos ambientais, se não forem devidamente tratados, podem comprometer o bem-estar social. Se por um lado a extração mineral gera divisas, emprego e renda para o município, por outro lado degrada o meio ambiente, podendo comprometer outros setores da economia como, por exemplo, o turismo.

Conforme concluído por Faleiro e Lopes (2010), alguns dos grandes desafios a serem superados atualmente são a racionalização das atividades de mineração, a mitigação e a recuperação das áreas impactadas por elas, buscando sempre o desenvolvimento sustentável. Especialmente no Brasil, a prática de lavra sem rigor técnico, com abertura indiscriminada de frentes de lavra, é muito frequente (PINHEIRO, 2002). As minerações de rochas ornamentais precisam ser melhor planejadas. Segundo Almeida (2006a), um planejamento bem detalhado, se possível com o desenvolvimento de uma lavra piloto ou experimental, possibilitaria a determinação de um melhor aproveitamento da rocha extraída e uma menor geração de rejeitos, definindo com maior precisão a viabilidade econômica do empreendimento.

Por fim, são necessárias as ações de políticas públicas, o monitoramento e a fiscalização, com o intuito de pôr um fim nas irregularidades, principalmente dos empreendimentos de médio e pequeno portes.

trado) - Programa de Pós-Graduação em Engenharia Mineral: Economia Mineral, Universidade Federal de Ouro Preto. 123 p. Outro Preto, $2006 \mathrm{~b}$.

BITAR, O. Y. Avaliação da recuperação de áreas degradadas por mineração na região metropolitana de São Paulo. Tese 
(Doutorado em Engenharia Mineral) - Escola Politécnica da Universidade de São Paulo, USP, São Paulo, 185 p. São Paulo, 1997.

BRUM, I. A. S. de. Recuperação de áreas degradadas pela mineração. Monografia (Especialização em Gerenciamento e Tecnologias Ambientais na Indústria) - Departamento de Hidráulica e Saneamento da Escola Politécnica. 22 p. São Paulo, 2000.

CARVALHO, E. G. de. Mineração, meio ambiente e desenvolvimento sustentável no Estado do Ceará: aspectos legais, econômicos e sociais. Fundação Edson Queiroz - Universidade de Fortaleza, Unifor, Brasil, 2004. p. 291-317.

CHAUHAN, S. S. Mining, Development and Environment: A Case Study of Bijolia Mining Area in Rajasthan, India. Kamla-Raj. J. Hum Ecol., v. 31, n. 1, p. 65-72, 2010.

COELHO, A. A. de M.; VIDAL, F. W. H. Métodos e tecnologias de lavra para a melhoria da qualidade e produtividade dos blocos de granito no Ceará. In: SIMPÓSIO DE ROCHAS ORNAMENTAIS DO NORDESTE, 4., Fortaleza - Ceará, 2003. Anais... Rio de Janeiro. CT2003-086-00, 2003. p. 180-188.

COSTA, B. M. Avaliação qualitativa das metodologias de lavra utilizadas na extração de rochas ornamentais no município de Santo Antônio de Pádua - RJ. Rio de Janeiro: Instituto de Agronomia. Departamento de Geociências. Universidade Federal Rural do Rio de Janeiro, 2009. 59 p.

DONAIRE, D. Considerações sobre a influência da variável ambiental na empresa. Revista de Administração de Empresas (RAE - Ambiental). São Paulo: EAESP/FVG, v. 34, n. 2, p. 68-77, 1994.

FALEIRO, F. F.; LOPES, L. M. Aspects of Impacts of Mining and Exploration Quartzite in Pirenópolis-GO. Ateliê Geográfico Goiânia-GO, v. 4, n. 11, p. 148-162, 2010.

FARIAS, C. E. G.; COELHO, J. M. Mineração e meio ambiente no Brasil-Relatório Preparado para o CGEE (Centro de Gestão e Estudos Estratégicos - Ciência, Tecnologia e Inovação). PNUD - Contrato 2002/001604. 2002. 40 p.

FERNANDES, F. R. C.; LIMA, M. H. M. R.; TEIXEIRA, N. $\mathrm{S}$. As grandes minas e o desenvolvimento humano das comunidades do semiárido brasileiro. Rev. Ciênc. Admin., Fortaleza, v. 15, n. 1, p. 105-132, 2009.

FERREIRA, G. C.; DAITX, E. C.; DALLORA NETO, C. Impactos ambientais associados ao desmonte de rocha com uso de explosivos. Geociências, São Paulo: UNESP, v. 25, n. 4, p. 467-473, 2006.

LIMA, F. S. P.; FALCÃO, C. L. da C. Impactos ambientais da atividade mineradora na Serra do Rosário para fins de extração de granito ornamental - Sobral-CE. Revista Homem, Espaço e Tempo. ISSN 1982-3800. Universidade Estadual Vale do Acaraú-UVA. Centro de Ciências Humanas-CCH, 2009. 11 p.

MATTA, P. M. Indústria de rochas ornamentais: rejeitos X produção limpa. Bahia: Departamento Nacional de Produção Mineral - DNPN/BA, 2003. 45 p.

OLIVEIRA JR., J. B. Recuperação de áreas degradadas pela mineração. Apostila do Curso Recuperação de Áreas Degradadas pela Mineração. I Congresso Nacional de Meio Ambiente na Bahia. Universidade Estadual de Feira de Santana, 1998.

PINHEIRO, J. R. Aspectos técnicos da indústria extrativista do setor de rochas ornamentais. Revista Rochas de Qualidade, São Paulo, n. 166, p. 60-74, 2002.

REIS, R. C.; SOUSA, W. T. Métodos de lavra de rochas ornamentais. REM: R. Esc. Minas, Ouro Preto, v. 56, n. 3, p. 207-209, 2003.

RIBEIRO, J. T. de M.; FERREIRA, G. C. Mineração subterrânea de carvão X comunidade no seu entorno: um exemplo de Santa Catarina. REM: Revista da Escola de Minas, Ouro Preto, v. 60, n. 3, p. 459-464, 2007.

ROCHA, C. H. B.; SOUSA, J. G. Análise ambiental do processo de extração e beneficiamento de rochas ornamentais com vistas a uma produção mais limpa: aplicação Cachoeiro do Itapemirim-ES. Enciclopédia Biosfera, Goiânia: Centro Científico Conhecer, v. 6, n. 9, 2010. 17 p.

SIQUEIRA, A. B. O Direito Ambiental na legislação brasileira: um contributo para o resgate da história. Revista Eletrônica Mestrado Educação Ambiental, ISSN 1517-1256, v. 9, p. 112-123, 2002.

SPÍNOLA, V.; GUERREIRO, L. F.; BAZAN, R. A indústria de rochas ornamentais: estudo de mercado 02/04. Bahia: Desenbahia - Agência de Fomento do Estado da Bahia, 2004. 47 p.

WILLIAMS, D. D.; BUGIN, A.; REIS, J. L. B. C. Manual de recuperação de áreas degradadas pela mineração: técnicas de revegetação. Brasília: IBAMA, 1997. 96 p.

Recebido em 14 de março de 2012. Aceito em 19 de junho de 2012. Publicado em dezembro de 2012. 